\title{
Reflexiones sobre la Independencia del Perú
}

\author{
Por Carlos Neuhaus Rizo-Patrón
}

En algunos escritos de aquella pléyade intelectual peruana que surge a fines del novecientos - generación peruanista- así como en varios, conspicuos escritores del presente siglo, vislúmbrase la deleitosa sugestión que les produce Gustavo Le Bon, escritor francés nacido en 1841. La exaltación que hace del alma colectiva puede tal vez apreciarse de un párrafo tomado al azar en una de sus obras. Y así expresará que "el individuo en muchedumbre es un grano de arena colocado junto a otros granos de areno también, a aquienes el viento mueve a su capricho" (1). Y afanados más intensamente acogerán la prédica Comteana quien afirma en algún momento que el espíritu positivo no reccnoce la existencia del hombre propiamente dicho $y$ "que no puede existir más que la Humanidad, puesto que todo nuestro desarrollo se debe a la sociedad" (2).

Muchos pensadores, al intentar explicarse los hechos del pasado han sido subyugados por el afán muchas veces premeditado e irreflexivo de supeditar los acontecimientos históricos al tráfago avasallador de lo social, olvídanse del individuo, germen incesante de las evoluciones que protagonizan las multitudes.

Pese $\alpha$ su reconocida inclinación filosófica, Javier Prado no osa cubrir la significación individualista -o de élites que es suma y no fusión de individuos - del gesto independentista. Y aunque exprese que la raza indígena no ha podido soportar ya más sus sufrimientos y que todo aquel rencor se personificó en Túpac Amaru, luego admitirá que las razas en el Perú, separadas, divorciadas, no llegan a formar un 
cuerpo homogéneo y por ende estima que "no han existido tampoco los sentimientos $y$ esfuerzos comunes, los ideales y las intereses nacionales, que son los únicos agentes que pueden conducir a los pueblos por el camino del progreso" (3).

A extremos llega sin vacilar el afanoso publicista Jorge Cornejo Bouroncle, al aseverar que "los caudillos, los dirigentes, eran guiados, como nunca en la historia, por el alma de las masas". Y reforzaría este dicho su convicción que las nuevas ideas no ejercen influencia alguna en la rebelión de Túpac Amaru (4).

Hcy es frecuente y en el futuro puede serlo más intensamente aún, suponer que la independencia peruana es un fenómeno social, eminentemente colectivo. Se entiende que el gérmen del descontento se posesiona lentamente de la sociedad y que luego fluye en el ánimo de los caudillos que representarán un sentir general.

No podemas creer, infortunadamente que en nuestro suelo el descontento genera una reacción definitiva en las masas. Lo produce, en comunión con otros factores, en las élites pensantes. Y el movimiento, por extraña condición, se toma inverso. No es ascendente de masas a élites sino descendente de élites a masas.

Es preciso analizar los movimientos revolucionarios que se producen antes de 1821 para comprender su carácter no colectivo sino primordialmente individuálistád dé élites.

\section{"Jorge Puccinelli Converso»}

\section{I}

El motín, cuando Antequera es ajusticiado, no pasa de una explosión de reproche colectivo, acicateado por sacerdotes franciscanos, cuya reputación de guerreros no es precisamente verosímil. Síntoma de la base espontánea y motinesca de aquel incidente, es la facilidad con que el Virrey Armendáriz, Marques de Castelfuerte, presente y a caballo en la plaza, somete y pacifica al populacho y a los exitados franciscanos que al siguiente día, harían larga hilera tras el confesionario.

La rebelión de José Gabriel Condorcanqui, discutida ilustradademente en lo que atañe a su finalidad, aparece clara en cuanto respecta a sus motivos. El hostigamiento insensato pero fecundo y ya se- 
cular del conquistador a los indígenas determina la actitud de 1780 . En lo de Tupac Amaru existe un trágico sedimento económico que acicatea profundamente. Es el caso determinar específicamente si este movimientc. importa una instancia de la masa al caudillo o si éste recoge la injusticia y luego insta al pueblo. Acaso la explicación puede hallarse en el relato de Carlos Daniel Valcárcel. "Terminada la sanción revolucionaria -expresa- el caudillo arengó en quechua a los indígenas y recordando las pasadas grandezas señaló la tristísima condición en que al presente vivían debido a las repartos mercantiles, la mita, los obrajes y las innumerables cargas económicas que los abrumaban. Y en prueba de sus propósitos constructivos, declaró que aceptaría a los individuos que voluntariamente quisieren colaborar, "desabrochandc." la idea que hasta entonces habían tenido oculta".'

El verbo, no muy galano pero acertado, que se usa al final del párrafo, sintetiza este fenómeno. Tupac Amaru "desabrocha" descubre, a los indígenas sus posibilidades de rebelión. De otro modo, aquella dócil y sufrida raza, tal vez habiere continuado soportando la tortura de los siglos. Es necesario que surja un individuo para despertarles.

¿Pero quién es Tupac Amaru? ¿Es el indígena que sufre a la par que sus coetáneos? No es el casc. Condorcanqui, dueño de los cocales de San Gaván, es hambre de dineros y de créditos. El observa esta agreste realidadibY reacciona contratellas Luego, el movimiento tiene una fuente innegable de reflexión cosa impropia de una masa, eminentemente aturdida o cegada. Acaso sea dable suponer que la gesta de 1780 tiene también el aspecto del descendimiento de individuo élite a masa.

Las más de aquellas conspiraciones ci alzamientos que se producen antes de 1821 son inspirados por grupos y no van más lejos de la tertulia clandestina. Otros sin embargo, envuelven repercusión multitudinaria. Y en cuanto atañe a los últimos ¿puede creerse que son eclosiones sociales? Francisco Solanc de Zela, en 1811, enardece a los tacneños. No a la inversa. Su famosa arenga en la Pampa de la Disciplina o Caramolle prueba inequívocamente el carácter de la insurgencia. No tanto quizá por la fogosidad de sus palabras sino por el desfallecimiento que le scbreviene. Al caer Zela, ¿la rebelión prosigue $\circ$ agoniza?. El declive que sobreviene señala la base caudillesca que posee. 
Es un tanto más difícil juzgar la rebelión de los Angulo, impropiamente llamada de Pumacahua. Los verdaderos promotores son lis primeramente nombrados. Cabe inquirir, sin embargo ique significación tiene el anciano Brigadier y la masa indígena que participan?.

La figura de Pumacahua se ha elevado demasiado. Por le fuer$2 a$ de los epítetos y por el vigor indetenible de la ignorancia. Sabido es que participa activamente en la debslación de la insurgencia ìe $\mathrm{Tu}^{-}$ pac Amaru y que a mérito de ello obtiene galones en las armas del Rey. Cuando los Angulo traman esta rebelión se valen del anciano para conquistar la adhesión indígena. Le toman como instrumento, en ciertc modo. Luego le convierten en Presidente de la Junta que se instaura en el Cuzco - la primera en territorio peruano- $y$ le toman finalmente, revolucionario. Su actuación, pese a la muerte simbólica que alcanza, se ve empequeñecida por su actitud frente a la instructiva que le siguen. Sus declaraciones son deplorables. Lejos de la gallardía y parquedad que han lucido otras patriotas, Pumacahua se dobla, proclámase inocente, engañado por los Angulo y reniega de su gesto. Mejor y más digna muerte tiene el altoperuano Murillo, aunque en vida vacila y oscila mucho más.

El Brigadier, quizás pcr patriotismo acaso por sugestión, arrastra al indígena a la contienda. Pero la masa.no lo arrastra a él. Lo convierte insurgente unaßélitel: olácdedos Anguló.

Seguir este sendero de examen iconducirá a nuestro juicio, hacia la determinación del individualismo de las élites como gérmenes motrices de lo ocurrido dentro del actual Perú, antes de 1821. Inclusive José Carlos Mariátegui se verá precisado a exclamar que "si la revolución hubiese sido un movimiento solo de masas indígenas, o hubiese representado sus reinvindicaciones, habría tenido necesariamente una fisonomía agrarista". Y esta, bien sabido es, no se da (5)

Jorge Basadre creerá que la independencia es un fenómeno de élites, "resultante de una obra urbana y criolla", anunciada con ciertas inquietudes nacionalistas y culturales en la élite intelectual cortesana de los virreyes (6). Y Jasé M. Valega expresa que "sólo las minorías selectas sentían, coma realidad espiritual, las nuevas verdades legales europeas". (7)

Aunque la idea de libertad es conocida difusamente, la vocación de independizarse es privilegio en el Perú de muy pocos. En las memorias de Pruvonena - las que lamentará el biznieto al siguiente siglose lee, respecto al pueblo que "paco a poco era necesario irlos encami- 
nando y preparando sus pasos, asíicomo a los niños se les dá el alimento conveniente para despecharlos". (8)

Acaso en otros pueblos de América puede elevarse más la significación de lo social. En el Perú, o por decirlo más ajustadamente, dentro de los límites de las Audiencias de Lima y Cusco, el fenómeno es fundamentalmente de élites y caudillos cuya principal desventura ha sido, quizá no haber llegado intensamente al pueblo.

Por ello alcanzará vigencia en la revolución americana, el "individuo histórico" a que se refiere Hanotaux, que es "por excelencia, el gran hombre, el profeta, el santo, aquel que ha cogido, prolongado, realizado en su juicio, en su voluntad y en su obra, las aspiraciones de una generación y de su tiempo, para darles un impulso nuevo. Por ello también afirmará el mismo que "sin los héroes no hay progreso ni historia": La vida de la humanidad no merece ser contada...". (9)

\section{DETERMINISMO DEMOGRAFICO.}

\section{CAPITULO SEGUNDO}

Desde las sesiones, no muy apacibles siempre, de la Sociedad Patriótica que establecen en Lima San Martín y Monteagudo hasta nuestros días, ha sido preocupación saludable $y$ frecuente indagar las causas que retardan orgetraen qủnindependencia"en el Perú. Tres reuniones de aquel Areópago político con vestidura académica, se dedican a estudiar la cuestión.

Mas tarde, dos extranjeros, Mitre y Vicuña Mackenna, prodigan generosas explicaciones. Luego se afanarán los historiadores peruanos por las justificaciones ineludibles. Y en verdad que la tarea no puede considerarse concluída.

Muchas son evidentemente las razones. Y entre ellas, vale considerar un aspecto social que colige inquietantes revelaciones. No se pretende llegar a conclusiones. Ella será tarea de eruditos y especialistas. Es intención por ahora plantear un derrotero.

Sin poder precisar cifras exactas, puede estimarse que en el Alto Perú, a principios del siglo diecinueve, la población está compuesta por una inmensa mayoría indígena y mestiza. Los españoles constituyen una ínfima porción.

En la Nueva España, de cinco millones de habitantes que aproximadamente se cuentan, sólo existen ochenta mil españoles. En Bue- 
nos Aires, los peninsulares representan también una escasa porción. $Y$ en Chile, menos de la sexta parte. En casi todas aquellos países, la población mestiza es varias veces superior a la hispánica.

¿Y en el Perú como está compuesta la población?. Según el censo mandado practicar por el Virrey Taboada y Lemus, la población asciende a 1.070 .677 y no a 1,070,122 como errada aunque intrascendentemente totaliza Lorente. (10) La comprobación interesante surge de analizar como está compuesta esa población. Y así se advertirá que existen 608,894 indios, 244.436 mestizos, 135,755 españoles, 41,256 castas libres y 40,336 esclavos. En el Perú, a diferencia de otras países hispano americanos, la proporción de españoles es considerablemente alta.

¿Qué consecuencias puede deducirse de aquello?. A nuestro propósito una y muy cardinal. Es mucho más factible que en México, par ejemplo, $3,600.000$ criollos $y$ mestizos dominen a 80 mil españoles que 244,000 mestizos peruanos subyuguen a 135,000 españoles. Máxime cuando éstos concentran el poderío militar y económico.

En el Alto Perú se da el primer anuncio de independencia próxima. ¿Cuál es la proporción de españales? Si bien no es dable precisarlo con exactitud en este momento, es sabido que su número es infimo. En Bs. As. y Chile acontece cosa igual. Resulta muy comprensible que haya existido una mayor facilidad para someterles dentro del proceso de las juntas.

Pero es el caso davertir que noi se tomal fa idea de raza en este examen, ni siquiera a la manera como la reconmendara en 1944 el Congreso de Sociología que se reunió en México. En este factor demográfico juegan las nacionalidades, blancos contra blancos e inclusive indios contra indics. Pero se agitan y banderizan godos, chapetones o gachupines contra criollos. Jorge Juan y Antonio Ulloa expresan que "basta ser europeo o chapetón, como les llaman, para declararse contrario a los criollos: y suficiente el haber nacido en Indias para aborrecer a los españoles". Y aunque es obvio insistir sobre el punto, vale recordar que Riva Agüero, en el célebre folleto de las "28 Causas" destaca que en 1816 el antagonismo entre criollos y chapetones, apelativos cuyo carácter peyorativo revela de suyo la rivalidad infranqueable. Pero luego advertirá, cosa de sumo interés, que ambos son enemigas de la raza indígena. Esta aseveración contribuye a justificar la actitud bipolar de los indios en las guerras posteriores.

El crecimiento de la población mestiza y aún el menos considerable de la criolla hállanse en relación de progresión geométrica frente 
al aumento de población peninsular que elévase sólo en progresión aritmética. Si bien la inmigración es incesante no lo es tanto como el crecimiento vegetativo de los aposentados en estas latitudes. Ello trae cconsigo, inexorablemente, la convicción que la independencia de las colonias hispanas hubiere devenido en caso forzoso, con los años. De no mediar los decisivos acontecimientos de principias del siglo pasado, la marejada criolla habría sepultado, lenta pero inconteniblemente, la oleada hispánica. O dicho en otros términos, es el ríc que forzosamente habría alcanzado al océano.

Puede pues, en síntesis, concluirse todo aquello con la idea que la independencia ha sido un fenómeno necesaria, inexorable, que hubiere venido quizá a mediados o fines del siglo pasado, de no mediar los acontecimientos peninsulcires de 1808. Esto es lo que podría considerarse un determinismo demográfico deniro de la explicación independentista.

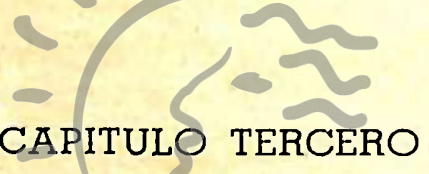

\section{SINGULARIDAD DEL MOVIMIENTO PERUANO.}

Muchos han sido lós reproches que se han concedido sobre la actitud peruana frente a la reacción libertaria americana del siglo diecinueve. Por sólo "mencionar un párrafo baste recordar que Domingo F. Sarmienta diría de Lima que era "ciudad antes sin industria, posada de empleados, sede arzobispal, patria de santos... no tenía que hacer con la independencia porque nadie tenía para que ser independiente, Y sí mucho que perder en serlo". (11)

Sarmiento traduce una impresión muy generalizada en América. Valga apreciar debidamente que otro argentino, Mitre, tratará de justificarnos y un chileno, Vicuña Mackenna, con mayor generosidad aún, querrá destacar la significación de los peruanos en aquellas guerras.

Tarea ha sido y será de los peruanos explicarse, justificarse. Razones y argumentos existen y son preciosos. Mil causas retardan la independencia en nuestro suelo; motivos de suyo disímiles que no se dan en otros países. Baste citar el anteriormente mencionado de la composición social. Ningún país a excepción de España, alberga tantos españoles en el siglo XVIII.

Justificable en sumo grado es el propósitc que anima a José Agusto de Izcue al escribir diversos artículos sobre los peruanos y su 
independencia, trabajas que recopilaría en un folleto, el año 1906. (12) Encomiable y necesaria ha sido la tónica infundida por los textos escolares. Al extremo que las actuales generaciones han quedado posesionados del innegable y valioso aporte nacional en aquellas campañas. Los peruanos no necesitan ser convencidos. Sin embargo, el lector extranjero sí.

Si bien está dicho y entendido, la lucha por la independencia constituye una unidad en el tiempo y en el espacio. Ello, no obstante, no contradice la impresión que se tiene, del carácter peculiar que asume la contienda libertaria en nuestro suelo. Acá se dan hechos singulares, disímiles. Por ello tal vez la reacción es diversa.

Ningún país de América ha tenido un Abascal. La tenacidad indomable, la sagacidad penetrante y la energía rotunda de aquel Virrey sirven para destruir la "patria vieja" de los chilenos, la "junta tuitiva" de la Paz y la junta que Ruiz de Castilla preside en Quito. Si esto logra Abascal en la periferia de su yirreynato. ¡Cómo no lo habría de alcanzar en la sede misma!

Es también original la circunstancia de no haberse sometido, el anciano virrey, a las maquinaciones de los patriotas como lo harían otros en América. Hay un plazo invisible e inxeplicable que lo sujeta a la sombra del "deseado" Fernando VII.

Ciertas autores, isin lembargo, que pretenden descubrir en Abascal móviles no precisamente lcables. ¿Por qué, se preguntan, cuándo se convoca a reunión de notables para determinar el partido a seguir con motivo de los sucesos de España y las revueltas americanas, no sigue Abascal los consejcis, "a lo Ulises", de Manuel Arredondo, Regente de la Audiencia limeña? ¿Por qué no sigue las sugerencias del Brigadier Villalta? ¿Por qué se empeña en hacer la guerra a todo tran$\mathrm{ce}$ ?

Sabido es que el Virrey pertenece al círculo del reprobable Ministro Godoy. Sabido es también que, antes y después de 1808, el favorito de Carlas IV y María Luisa cuenta con un respetable elenco de enemigos entre las gentes de aquella época godoyesca. Y es tradición consentida que el temor a Godoy le incita a promover la guerra contra la rebeldía.

Asevérase también que se halla en entendimientos con la Infanta Carlota Joaquina, cuya actitud dudosa no favorece precisamente a su patria de origen. De todos modos, Carlota mira por y para el Portugal. $Y$ no faltan temerarias aseveraciones sobre un supuesto entendimiento 
de Abascal con Bonaparte patentizado éste, se expresa, cuando la jura a Fernando en Lima por la aparición de cartelones con la inicua leyenda de "Viva José". Finalmente, hay también quienes le suponen el deseo de entronizarse, en Lima.

El ánimo de aquel Virrey, ha estado indudablemente conmovido el año de 1808. Las noticias de España resultan cada vez más agrias. Las reyes dimiten, Madrid es herida con heroísno el 2 de Mayo, José Bonaparte, secuela del dominus orbis, se torna soberano y su efigie de romano decadente aparecerá en las monedas. Pese a todo, el 13 de Octubre de 1808 se jura fidelidad a Fernando. Y con ello Abascal dicta su sentencia y el organismo virreynal peruano recibe una inyección estimulante que le permitirá sobrevivir algunos años más.

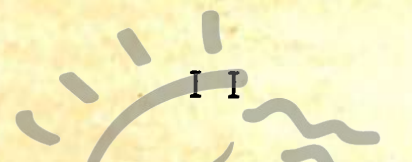

Es curicso advertir que en ningún territorio de la Audiencia de Lima se proclama Junta alguna a raíz de los sucesos de España. En Cuzco, que es Audiencia distinta desde 1787, se instalará una suerte de Junta cuando la rebelión de los Angulo y Pumacahua. Sin embargo, la naturaleza de aquella reunión es algo disímil a la de otros países. Esta ausencia de Junta en Lima es de suyo, fenómeno que tipifica y singulariza la gesta libertaria peruana. ¿Y qué razones puede hallar la historia para explicarse la actifud limeña? ${ }^{-}$Es ${ }^{r}$ posible que das : de una parte la presencia de Abascal y de otra la acreditada circunstancia que Lima es España, o el Madrid pequeño como se le dirá muchas veces.

Se ha repetido con frecuencia que el Perú es Lima. Pero entonces, vale advertirlo, no todo el Perú es Lima. Hasta mediados del siglo pasado, cuando desaparece ya el separatismo sureño, las provincias australes se hallan desligadas en mucho a la capital. Reflejo de ello lo constituyen los graves y multitudinaries intentos rebeldes, que se dan en el Sur y no en el norte peruano. Túpac Amaru, Zela y los Angulo traen consigo insurrecciones sureñas.

En las provincias centrales, si bien no se conmueven con tanta intensidad, los casos de ascnadas y conspiraciones también resultan frecuentes. En Lima, las insurrecciones casi no trascienden de etapa intelectual. Por ello, es dable suponer que las provincias y la capital responden de modo diferente al estímulo de libertad. Cabe pensar luego que la posibilidad de rebeldía está en razón directa con la distancia a que se halle Abascal. 
La intervención peruana en la guerra por la libertad de su suelo es asunto que ha sido tratado muy exhaustivamente. El Album de Ayacucho trae un valioso documento que testimonia los nombres de quienes actúan en las campañas. No es el caso repetir ahora que Salaverry y Odriozola -en unión de muchos otros- se presentan al Ejército Libertador, ni que los peruanas actúan decisivamente en Pichincha - Mayo de 1822- en Junín y Ayacucho. Tampoco se ha de mencionar la acción silente, cauta a veces, sonora y arriesgada otras, de los llamados precursores intelectuales, desde la contienda entre Baquíjano y Villalta por el Rectorado de San Marcos hasta los días en que furtivamente, valiosas comunicaciones cifradas van $y$ vienen de Huaura a Lima.

No es el caso tampoco destacar la actitud decidida $y$ en veces reñida con la sotana de las sacerdotes patriotas. Acá se dan émulos de aquel clérigo salteño, no de coro sino de campanario, Ildefonso Muñecas que llega a exclamar que es menester echarse sobre los enemigos y despedazarlos......

Pero sí interesa resaltar que la mayor parte de los emisarios secretos que envía San Martín a Lima son peruanos. Y es gente que arriesga cotidianamente la vida. Así lo harán el supano Francisco Vidal, el limeño José Paredes, Landa y Vizcarra, Lorenzo Valderrama, José García y Franciscoo Fèrnández de Páredes. allos se vincularán en Lima con los Riva Agüero, los Pérez de Tudela y tantos otras cuya relación puede verse en el "Album de Âacucho" Y en documentos existentes en la Biblioteca de Lima. Hora es de orientar una concienzuda investigación sobre las actividades trascendentes y sigilosas de estos arriesgados peruanos cuyos nombres permanecen huérfano de los homenajes oficiales.

\section{I I}

El proceso de las rebeldías peruanas anteriores a la proclamacióń de la independencia merece una revisión. Suele trazarse un común denominador, que abarca para unos desde Antequera, para otros desde Túpac Amaru y no falta quienes se alejen hasta la rebelión de Marco en el Siglo XVI.

Sin embargo, es preciso trazar dos ciclos. Uno concluye con el proceso de Aguilar y Ubalde. Otro empieza con los intentos de 1809 (los hermanos Silva). Precisa advertir sin embargo, que la actividad 
de los liberales peruancs desde 1780, aproximadamente, resulta antecedente del segundo ciclo.

¿Y qué razón existe para dividir en dos etapas todo aquello que generalmente se envuelve en una? Baste analizar el carćcter de cada mcvimiento para comprender esta partición no precisamente metodológica sino fáctica.

La insurgencia de Manco es, en verdad, capítulo postrero de la conquista hispánica. Los alzamientos de Hernández Girón y Lope de Aguirre constituyen rebeldías hispánicas de índole separatista. Lo de Gonzalo Pizarro, si bien fidelista, es también rebeldía de carácter hispánico.

Lo de Antequera, en 1731, está comentado antes. En ello no puede verse más que un motín espontáneo determinado por grave sacudimiento al noble e irrenunciable sentido de compasión humana. Lo de Juan Santos Atahualpa, personaje al parecer algo europeizado, traduce un clamor de justicia similar al de Túpac Amaru. La gravísima rebelión de éste último, importa un contenido social y económico como base primordial. La conspiración del minero Aguilar y del Abogado Ubalde, en el Cuzco y en el año 1805, la trágica "conspiración de la cortina", tiene relieves muy peculiares. Es promovida por personaje que ha recibido, sin duda, el contagio del iluminismc dieciochesco. Sin embargo, poseído de un aliento románticón /aspira a convertir en Inca. Y launque Belgrano pensara en términos equivalentes, resulta difícil incorporar esta intentona dentro del siglo decisivc, por una razón cronológica y otra doctrinal, que luego se esbozará.

¿Qué razón puede existir para pensar en un ciclo decisivo? Es entendible que la independencia en este suelo se produce por dos razcines primordiales : por descontento y por imitación. Ambos elementos no se dan antes de 1809. El descontento importa la innegable marejada social de reacción. La imitación entraña una respuesta al influjo de las doctrinas enciclopédistas cuya vigencia es innegable. (Porras dirá alguna vez que la independencia no se logra antes por exceso de reacción y jamás por falta de estímulo).

La conspiración de 1809 transcribe una réplica del abogado $\mathrm{Ma}^{-}$ teo Silva y del benemérito pica pleitos gallego Antonio María Pardo, principalmente, frente $a$ lo ocurrido en Quito - que es sabido en Lima el 6 de Setiembre- y frente también a los sucesos del año anterior en Chuquisaca y La Paz. En general, casi todas las intentonas, a partir de 
aquel momento poseen características similares. Y son ellas los antecedentes inmediatos de la República.

La agitación que se produce en Lima cuando el nombramiento de Baquíjano y Carrillo, envuelve innegablemente un propósito no bien descifrado pero virtual de alzamiento. Pese a la duda que abriga el historiador Riva Agüero sobre la presencia del Conde de Vista Florida, vale consignar que Torre Tagle, en relación auto laudatoria que recoge el Boletín del Museo Bolivariano en 1929 (12), ha admitido que en dicha agitación participan él, Baquíjano, Riva Agüero, Öúe, el Conde de la Vega del Ren y muchos connotados liberales. Y expresa - cosa poco verosímil-que le iban a nombrar "Jefe Supremo del Perú Libre".

El movimiento de los Angulo y Pumacahua trae consigo, está dicha, una Junta de Gobierno que preside el Brigadier ináigena. No puede desconocerse que si bien de explosión retardada, esta Junta sigue la misma línea de las foráneas.

Lo de Zela y Paillardelle en Tacna sabido es que se halla atado a Buenos Aires. Y así sucederá con la mayor parte de las conspiraciones, intentonas, alzamientos o asonadas como se les ha llamado a las que se producen a partir desde 1809.

\section{Bibliotec ${ }^{\mathrm{IV}}$ de Letras \\ "Jorge Puccinelli Converso"}

Resulta tarea de interés indagar las reacciones de los peruanos frente a los bochorncsos e ignorados entonces sucesos presentados cuando Napoleón asoma el Aguila sobre la cima de los Pirineos. Existe un curioso documento en el deplorable Archivo de la Real Audiencia de Lima, acaso inédito, que revala en verso ciertas ideas que se agitan en 1811.

Por este expediente se descubre que en Febrero de 1812 es dicta. da en Cerro de Pasco orden de captura contra Mariano Cárdenas, $\mathrm{Ma}^{-}$ nuel Rivera (alias "Guañari") y se manda inquirir "con el mayor sigilo" la conducta de dos sujeíos apellidados Tello y Robles.

Cárdenas revela en la instructiva que la noche del 13 de junio y al conjuro de chicha, aguardiente y guitarras cantan los llamados versos de la concordia; coplas armadas con motivo de la creación del Regimiento del misma nombre. Expresa además que el autor de las décimas es el religioso mercedario Mariano Aspiazu quien reside en Huánuco y es natural de Quito. 
Manuel Rivera depone que el Padre Aspiazu le ha comunicado que "venía el insurgente Casteli a defender a los criollos porque los europeas querían solamente gozar de los empleos y nada los americanos". Admite tener de veinticinco a treinta décimas proporcionadas por el Padre Aspiazu para que las hiciera circular pero, añade, no lo hace, pues ellas contienen "los pasquines que se pusieran en Pasco en la noche del día de Pascua de Resurrección" el año 1811.

¿Y cuáles son aquellas sonoras décimas que tanta incomodidad aparejan el brazo férreo del poderío virreynal? Salvadas por ventura todas, valga repetir algunas que otras, por el tono subido del denuesto y la invectiva, no es dable siquiera recoger. De ellas se entresacan las que siguen :

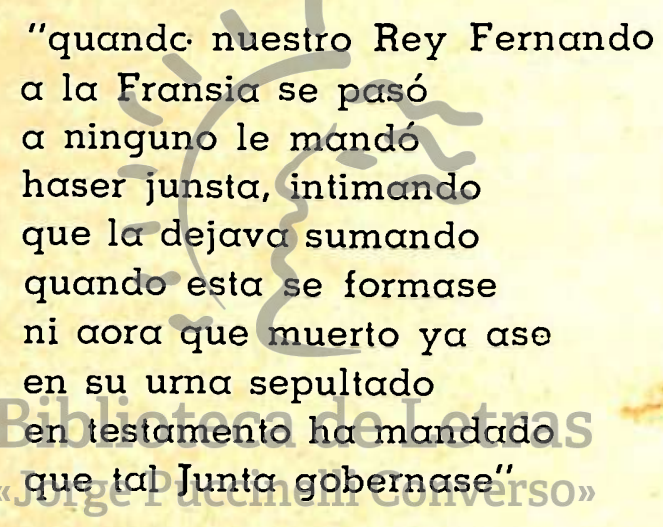

Pero sin lugar a dudas, la más expresiva de todas es la cuartilla reza como sigue :

"El Chapetón y el cricillo se unieron en amistad con la misma intimidad que un Gavilán con un pollo..."

Alguna tendría cierta tónica doctrinaria con sabor a alegato constitucionalista como

"Si con un poder Cumplido nuestro señor don Fernando huviera sedido el mando a la Junta, huviera sido 
puntualmente ovedesido el ccngreso de Regensia; mas como esta dependencia no consta que haya aprovado nuestro Dn. Fernando amado disputamos la ovediensia"

"Nuestro Septima Fernando que entre senisas yase nos ha consedido el pase aotro Govierno y Mando yapodemos ir quemando la antigua legislasion sin dar premio ala virtud que apoyava la opresion. se acavo la Esclavitud y altiva dominasion"
"Aora si algun chapeton fuese contigo Osado
sea deepronto castígadoverso"
con un gentil vofeton
no le consedas perdon
hasta noverlo humillado
y conforme el te ha tratado condesprecio y condesden le has de tratar tu tanvien sino llora su pecado"

El tono baja sensiblemente en las siguientes:
"Quatro picaros Juntaron otros muchos como ellos los que asiendo planes vellos la primera junta formaron luego despues, ya trataron de entregar su patrio suela 
$y$ anoser por el desvelo

de algunos patriotas finos

ya estos viles asesinos

habrian cumplido su anhelo"

"Quando en la Junta advirtieron

esta infame traysion

entre los de su nasion

alpunto se reunieron

y por si solos ysieron otra Junta de novedad

la arbitraria autoridad que la anterior se tomo ala Regensia paso con la misma nulidad"

"Sila Regia Potestad

Bhumildes covedesemosetras es solo porque savemos que a quella autoridad dimana de la deidad como deprinsipio y fuente lamas pura y exselente pero aotra potestad advirtrada con maldad ovedecer noes decente"

\footnotetext{
"Aquel genio dominante altivo, tosco y grosero, se mudara yolo infiero desde oi enadelante; aunque con rason bastante en pieso ya adular
} 
si estos podrán mudar aquel genio y maña vieja pues la zorra nunca deja c pro pension de rabar".

"El que no quiera dejar su altives, y mala maña ya puede volver a España avuscar ha quien mandar allá se harte Provar pedasillos de Perol porque aquí como Farol mui vreve lo hande colgar $y$ en el aire le harandar un agrasiado araevol".

OTROS VERSOS ADDONDE EL GRACEJO SE ENTREMEZCLA CON ADJETIVOS DE SUBIDOTONO CONCLUYEN CON ESTA QUE SABE A PROCLAMA
"Escucha por la razón no te siege el Egoysmo mira que es heroismo DEFENDED EL PATRIO SUELO Y procurar con anelo contener el despotismo".

OTRAS DECIMAS TRAIAN VERSOS COMO ESTE

"Despues qe. yalamaraña De la Europa esta savida Pueda segir unida nuestra America a la España?". 
Y CUANDO ANUNCIA QUE EN AMERICA DE "patriótico amor estén ardiencio los pəchus? CONCLUYE CON

"No hay duda que si havran

$y$ en firme prueva de esto azañas veran bien presto que a España le asomvraron".

Y HAY PRUEBA EVIDENTE DE NOTICIAS CUANDO SE DICE

"Auna glorioso acsion se prepara el Tucuman $y$ en Vuenos Ayres estan en mayor fermentacion con una admirable union estan ya todos resueltos a quedar primero muertas que dar su vrazo a torzer disen. Morir obenser o vivir en los desiertos".

\section{Biblioteca de Letras "Jorge Püccin SIGUE nverso"}

"Enchile yasean movido $y$ el Peru alto tanvien en el Cusco ay un vaiven que ha de dar un estallido en Arequipa ay un ruydo que anuncia la conmosion $y$ todos en conclusion para realisar su intento aguardan solo el momento de una felis Ocasion".

\section{Y TAMBIEN SE DIRIA}

"Con un teson inaudito se sostiene Santa Fe 


\begin{abstract}
y Caracas yaseve
que tambien toca su Pito

lo mismo susede en Quito

alqe. Cuenca se unira

y Guayaquil le dara

Su auxilio; pero entretanto

arebujada en su manto

la Zanba Vieja quehara?".
\end{abstract}

Estos versos han sido recogidos en la casa de Manuel Rivera, e inclusive la proclama que se pega en las paredes de Cerro la noche de Pascua de 1811. Con tales pruebas las autoridades españolas prosiguen las instructivas y el proceso continúa, irremisible e inexorable. Consta que a Mariano Cárdenas le encarcelan, le tienen a pan y agua y con ominosos grillos.

En Mayo de 1812 se remiten los actuados a Lima. Y con ellas van los detenidos. El asunto continúa bajo la misma advocación represiva que caracteriza a los tiempos. Pero el expediente muda totalmente de cariz. El FiscabEyzaguirre conspicúa patriota, dictamina que el sub-Delegado "procedió ex-abrupto con lo dispuesto por las leyes" Y estima que los inculpados han sido puestos en prisión sin fundamento alguno. La valentía del dictamen se revela una vez más cuando opina par una mera reclusión a sus claustros para el mercedario Aspiazu, figura aún desconocida para nuestra historia, pero es sacerdote de labor arriesgada e infatigable en provecho de la libertad. Por cierto que el Tribunal no toma en cuenta los considerados rotundas $y$ arriesgados del ilustre Fiscal.

Si bien Aspiazu no es hallado jamás, los otros conspiradores resultan condenados a penas diversas. Inclusive se encarcela a la mujer de Cárdenas, Pascuala Bazán, por no pagar las costas judiciales que demanda la instructiva seguida contra su esposo...... Gracias al indulto que se concede cuando la apertura de las Cortes de Cádiz, resultan libres los castigados por este sui generis delito de cantar, en trance alcohólico, coplas ajenas de tono más inclinado a la picardía que a la rebelión........ 


\section{CAPITULO CUARTO}

\section{ESPANOLES CONTRA ESPAÑOLES.}

Se ha preguntado y respondido a la vez José de la Riva Agüero, el historiador, "¿por qué no hizo Lima en 1810 lo que ha hecho tantas veces en la época republicana?". La respuesta no es dudosa - añade- : porque no quiso sublevarse, porque no lo entusiasmaba la causa de los revolucionarios? (13).

Ei notable historiador es preciso a este respecto. No se réiere al Perú sino a Lima. Así hemos de entenderle pues, de otro modo no sería posible conciliar ésta su idea, con la defensa que hace a la cooperación de la independencia, por el virreynato del Perú (14).

Es propósito de esta indagación, no averiguar la pasividad de Lima en 1808 - antes de 1810- sino inquirir por qué "no quiso Lima sublevarse".

Puede suponerse, en una palabra, que Lima no se alza contra España, porque Lima es España. Ya se ha advertido la altísima proporción relativa de peninsulares que viven en la sede del virreynato más importante de la América del Sur. Y Yaún los mestizos y criollos, acaso se sienten junto al Rímac, muchas veces más españoles que las mismos castellanos.

Se ha dado casos de americanos que fieles al monarca le sirven tenazmente contra los criollos. Andrés de Santa Cruz, es el Comandante de la caballería realista que cae prisionero a raíz de la acción de Cerro de Pasco, en 1820. Más tarde, el Libertador Bolívar promulgará un Decreto en Quito otorgándole excepcionales honores, el 18 de Junio de 1822.

El General La Mar que capitulará en el Callao y pasará al bando patriota es ejemplo típico del americano que sirve al Rey. Así también lo será Jasé Manuel Goyeneche, baluarte de España en el Alto Perú. El Arequipeño Antonio de Rivero y Aranibar figurá también en este cuadro de modo preponderante, cuando la sublevación de Zela. Recuérdese también que de Lima y con peruanos salen para Quito y Chile las expediciones que comandan los brigadieres - hispanas- Toribio Montes y Mariano Osorio.

¿Y qué es dable recordar sobre el soldado indígena? Vidaurre, en su "Plan del Perú" ha expresado que "en la guerra actual se ha 
visto que los indios son los mejores soldados : sobrios, fuertes, inamovibles. Jamás vuelven la espalda ni temen la muerte. El General Goyeneche creía justamente que con ellos era capaz de las mayores empresas". Y García Camba, el militar español dirá en sus "Apuntes para la historia de la independencia del Perú" (15), que las tropas del país tenían sin disputa algunas ventajas sobre las europeas, ya por la experiencia que habían adqurido, ya por no hacerles tanta impresión la continua variedad de temperamento, que a cada paso se experimentan en estas regiones, y ya en fin por su admirable sobriedad".

Este es el indio que aún pareciera ignorar el sentido de patria y se vuelve eficaz contrincante de las independentistas.

Y si bien los criollos serán baluartes del bando patricta, padecen en un principio de cierta confusión originada, es evidente, por la incertidumbre que traen las noticias de España después de la abdicación de Bayona. Así se explicaría como el muy representativo Toribio Rodríguez de Mendcza y el veleidoso Vidaurre, otorgarán donativos de cien pesos anuales para subvencionar los gastos de la guerra contra los americanos........

Y más vale no recordar lo ocurrido cuando se alza Condorcarqui. Entonces la masa indígena - ccn Pumacahua- también lucha contra el curaca de Tungasuca. Y los criollos y mestizos, como apreciará Corneja Bouroncle-Bl"estuviefonamás en contra que en favor del movimiento" (16).

He aquí el peruano que no reacciona. Símbolo acaso lo sería el clérigo Larriva, como asevera Raúl Porras, de ese pueblo "extraño en su maycr parte a la revolución, aún a la misma que se fraguaba en Lima, ridículamente fiel a Fernando VII, cortesano de los virreyes...... conspirador de palabra, haragán con sueldo de estado". Peruano como expresa el mismo historiador que no se "convence de la independencia hasta que se da con el ejército de San Martín en las calles".

Es precisamente de ese peruano que se lamentarán los escritores de más tarde y en saludable esfuerzo, se buscarán el modo de orientar la enseñanza de nuestra historia dentro de márgenes patriotistas que cculten y superen extraña pasividad del siglo pasado. Así lo hará, por ejemplo Mario Villarán en su "Introducción a la metodología de la historia" (17).

Conviene persuadirse que el fidelismo peruano -o limeño- $a$ España no es motivo de angustia ni de cerrar párpados a la realidad. Ca:sas innegables son la participación y la abstención peruana a la 
causa americana. Ambas actitudes representan ideologías que ya merecen el respeto de la historia. Repítase una vez más, Lima era España a fines del dieciocho y principios del diecinueve. $Y$ muchos criollos entienden que luchar contra los ejércitos del rey es traición. Y aquello se ha entendido como delito en muchos ánimos.

No por ello ha de creerse hoy que los americanos insurrectos han cometido tal pecado. No, en modo alguna. La historia sirve precisamente para exhumar, borrar o acentuar los juicios de los contemporáneos. Y ya en España, adonde San Martín merece antaño epítetc:s de baja crítica, hoy se respetan las figuras patriotas de aquella larga y ensañada contienda.

$N \bigcirc T A:$

Expresa Carlos Wiesse en sus "Apuntes de Historia Crítica del Perú". Edic. 1949: "Respecto del Virreynato del Perú, el favoritismo en favor de los españoles y el consiguiente alejamiento de los criollos de los destincs públicos fué menor que en otras secciones coloniales, y a ello se debió probablemente, junto con otras causas, el mayor apego que manifestaron las clases dirigentes al regimen realista en la época de la revolución por la independencia.

"Durante los trescientos años del períodos colonial aparecen en efecto, desempeñando puestos de ministros toggdos en los Consejos y Audiencias de Indias, Filipinas y España (número reducidísimo en estos dcis últimos países) 136 nacidos en el Perúi llegan a la dignidad de Arzobispos y Obispos 98 y sirvieron como generales, brigadieres y jetes, 63"'.

\section{CAPITULO QUINTO}

\section{NAPOLEON, LIBERTADOR DE AMERICA.}

Javier Prado concluye en su "Estado Social del Perú durante la dominación española" que "la revolución y luego la independencia americana fueron hechas necesarios, ineludibles, después de la revolución francesa y de la emancipación de la América del norte".

Hoy nos permitimos suponer que si bien la independencia fué hecho necesario e ineludible, no lo ha sido a raíz sólo de lo francés y de lo americano. Los escritos del ginebrino, de Voltaire, de Montes- 
quieu y de tantos otros son lecho de rosas sobre el que dispútanse los americanos por descansar aunque hubieren de cansarse para ello. La independencia de las trece colcnios es acontecimiento cuya influencia sobre el fenómeno hispónico ha sido sobrevalorada. Su naturaleza, eminentemente económica, le diferencia un tanto de la fisonomía que poseen algunos movimientos sudamericanos ccmo el peruano. Entiéndese mas bien que el bien que el reflejo del norte se da a la hora de constituir las repúblicas. Entonces nuestros congresales, poseídos de un capricho mimético, se dan a la imitación y claman par un federalismo exótico.

Puede aceptarse, acaso, la impresión que dichos trascendentales movimientos no motivan que la independencia de España se de en 1810. Mucha mayor ingerencia tiene, a nuestro juicio, el caos que se produce en la Península cuando Napoleón decide "rescatarla".

Al rey español se le ha respetado en América sin obstar la persona ubicada sobre el trono. Se ha consentido inclusive aquellas frivolidades amaneradas y dudosas de la época goyescas o godoyesca. Se ha llamado "deseado" al funesto Fernando VII. La atadura ha sido muy recia. Por ello, cuando Napoleón instaura al indigente mental de su hermano, surgen en la Península las descantadas Juntas, comprensiblemente tuitivas de los derechos del monarca legítimo.

En América sejda un caso paralelo. Levántanse también Juntas. Sabido es que resultan luego pretextos de autonomía. Pero aquellos organismos, no se habrían dado espontáneamente. Se crean porque en España surge la matriz. Y aquella institución típicamente española a su vez, se produce como consecuencia de la intervención napoleónica.

Este aparente silogismo encierra una realidad innegable. Ya Mitre lo ha dicho algunos años atrás y el sentido común, antes quizás. En la "Historia de San Martín y de la Emancipación Sud Americana" (18) anota que "no puede desconocerse que sin la invasión napoleónica a España en 1808 y la desaparición accidental de la dinastía españala, la revolución se hubiera retrasado..."

$\mathrm{Y}$ el erudito Pablo Patrón, en el comentaria que hace al discurso de Javier Prado de 1894, se pregunta ¿qué obra con mayor intensidad en la génesis de la independencia, si el estado de dislate o incoherencia de España a partir de Aranjuez o la condición inhóspita del habitante americano desde mediados del setecientas?

Se ha dicho, en un principio, que Napoleón resulta libertador de América. Precisa distinguir que el corso no representa influencia di- 
recta. Nada tiene que ver con América, aunque se haya fantaseado un tanto al respecto. Pero si es permisible creer que Napoleón determina la época en que se produce este hecho.

De otro modo, la autonomía, cosa forzosa, es posible que hubiere llegado algún tiempo después. Ácaso cuando ya el criollismo hubiere alcanzado cierta muelle senectud histórica...

\section{CAPITULO SEXTO}

\section{RAZONES Y SINRAZONES.}

Se ha expresado anteriormente que la independencia ha sido un movimiento de élites. Son los criollos y los mestizos los que abogan más intensamente por la libertad en el Perú. Por ello, cuando se revisan los motivos económicos que inspiran ese mcrimiento, debe atenderse con primacía a los que han praducido malestar en las élites. Esto no significa desatender la deplorable condición del indio. Pero bien es sabido que su condición no muda con la independencia. Y aún para el criollo, la principal variación que viene con la victoria de Ayacucho es la libertad de comercio, cosa que jamás habrá resultado permanente en el futuro.

Si la revolución de Tupáa Almarun hubiere triunfado, otro sería el acento de nuestro himno libertario. Entonces nos habríamos aproximado sensiblemente al fenómeno norteamericano. Entonces la ley de la melaza y, o el "the show" de Boston hubieren alcanzado sus equivalentes locales.

Pero el carácter eminentemente idealista de aquella lucha, vuelve muy difícil pensar que se obra por motivos económicos.

La principal finalidad que ha tenido el dinero en aquellos tiempos ha sido la de retardar. Recuérdese que las arcas se encuentran más colmados en el Perú que en otro país sudamericano. Y ese dinero sirve como nada para vencer las guerras.

La situación económica de los criollos en Lima no es de penuria, precisamente. Claro está que las fortunas se hallan principalmente en manos de españoles. Pero comerciantes ricos hay en el Perú muchísimos. Y algunos comprarán títulos de nobleza, como el primer Conde de Vista Florida, para legarlo luego, con acopio de dineros, además, al ilustre limeño Baquíjano y Carrillo. 
Se ha exclamado muchas veces que la carestía de los artículos es causa de desequilibrio económico. El aserto peca de error. El desequilibrio no se produce porque en Lima un quintal de hierro en aquella época costara 100 pesos cuando su precio normal en Panamá es de 25. La crisis tampoco sobreviene cuando la capacidad adquisitiva de la moneda desciende. Ella se produce cuando el consumidor carece de medios de pago para afrontar las alzas de precios. ¿Podría aseverarse que en aquella época no se perciben rentas cómodas en Lima por la ociosidad en que generalmente viven los criollos?

$Y$ si hemos de suponer que dichas rentas no alcanzan, entonces para los gastos vitales ¿puede aseverarse que alguna vez en nuestra historia se ha dado ese rarísimo fenómeno del equilibrio económico? Los estados de crisis económicas pueden determinar grandes movimientos sociales. Ello es innegable. Pero las determinan cuando el pueblo llega a un estado de saturación.

$\mathrm{Si}$ se quiere interpretar la historia con supuestos y con olvido de los hechos, como muchas veces se ha intentado, cualquier afirmación resulta posible. Pero es preciso reparar en lo ccurrido a principios del siglo pasado para hacer aseveraciones de esta índole.

Durante los más de los años virreynales, el impuesto de almojarifazgo grava duramente las importaciones y expartaciones. El Reglamento de Comercio y Aranceles que dicta Carlos III en 1788 reduce dicho impuesto.

La alcabala "-gravamen sobre toda transferencia de bienes muebles y inmuebles, inclusive cuando se exportan - sí puede considerarse elevada. Al final de la época virreynal alcanza a un $10 \%$. (En la Nueva España redituará hasta el $15 \%$ de los ingresas fiscales). Hoy día, si bien extinguida la alcabala sobre las transferencias de bienes muebles, asciende sóla $\alpha$ un $5,5 \%$ sobre los inmuebles. Puede arguírse que la situación por ese lado es más benévola, actualmente. Sin embargo, los impuestos sobre la exportación e importación son muchísimas mayores. Y los últimos afectan directamente la economía del consumidor.

Antes no existían los altísimos impuestos que hoy cobra el fisco sobre los sueldos, rentas y utilidades. El criollo de entonces no alimenta al fisca como lo hace el peruano de hoy.

El estanco del tabaco, fuente valiosísima de succión gubernamental, proporciona entonces utilidades de más del $100 \%$. Hoy, el mismo estanco "sólo" percibe utilidades que ascienden, en ciertos casos, al $50 \%$. Y todo ella repercute sobre el consumidor. 
En esta versión somera de aquel importante capítulo, tratado intensamente por Economistas de indiscuiible valor, como César Antonio Ugarte y Emilio Rcmero, no se pretende sentar opinión alguna. Sólo cabe expresar la impresión que si bien lo económico ha tenido significación en la lucha por la independencia del Perú, dicha ingerencia no ha sido lo suficientemente intensa como para determinarla. En otrc término, no se ha dado en nuestro suelo el caso de los Estados Unidos y ni siquiera el de Buenos Aires.

\section{CAPITULO SEPTIMO}

\section{PREEMINENCIA DE LO IDEOLOGICO SOBRE LO BELICO.}

No puede menospreciarse la circunstancia que el primer alzamiento sudamericano se dá en la Universidad de Chuquisaca, el 25 de mayo de 1808. Este hecho, si bien no decisivo, acentúa de sobremanera la impresión que se tiene del carácter primordialmente intelectual del movimiento independentista americano. Baste inquirir por los precursores de la revolución y siempre se hallarán nombres de figuras académicas, de doctrinarios y pensadores.

En el Perú sẻda un unaso similar. Puede estimarse como precedentes al ciclo decisivo de conspiraciones, el elogio a Jáuregui que dedica Baquíjano en 1781 y luego la disputa entre Baquíjano y Villalta por el rectorado de San Marcos en 1783. Ähí aparece ya el germen divisionario entre criollos y españoles. Ambos acontecimientos son de carácter o vestidura intelectual.

Vendrá luego la Academia Filarmónica y la Sociedad de Amantes del Pá́s. Se publicará el Mercurio Peruano, cuyo significado de aglutación es altísimo, pese a la idea que sobre la exageración de su importancia se ha formado Riva Agüero.

La acción precursora de Rodríguez de Mendoza en Lima y de Chávez de la Rosa en Arequipa dicen todo a este respecto. La patria será de los carolinos limenses y de los jeronimitas arequipeños en 1821.

La idea, con toda su brillantez y severo contenido, sobrecoge a los intelectuales peruanos. Ellos querrán volverse militares a veces y acaso en ellc estribe mucha parte de sus fracasos. Y los militares genuinos - si los hay antes de 1821 - responderón al imperativo del intelecto que sublimiza su lucha alejándola de la nefasta contienda muda de sable a sable, que tantas veces se da en el Perú. 
Acaso los españoles son derrotados entonces, porque les falta el aliento anímico, el impulso infatigable del ideal. Ellos defienden. La lealtad les mueve. Y aunque causa como esta, és noble de suyo, no lo es tan intensamente como la lucha por la libertad.

Nuestros militares patriotas han sido, como dirá Jorge Guillermo Leguía, ignorantes, bisoños, montoneros, sin sentido de táctica ni conocimiento de estrategia (19), en aquel arte de guerrear que habian de ejercitar ultimamente algunas veces, en Africa y en propio suelo contra Napoleón. Sin embargo, la idea derrota al fusil, el pensamiento subyuga al sable.

Por ello escribe recientemente Enrique Ruiz Guizazú, que "la antorcha de la revclución se enciende sincrónicamente en los grandes centros de la cultura colonial; están a su frente los doctores de las universidades, los mismos a quienes los naturales miraban con respeto y temor" (20).

El guerrero en la lucha americana es el chatria que emerge de los brazos del Brahama. Y ese brazo es movido a diestra y siniestra por ideas directrices. En ello radica uno de los caracteres más apreciados del movimiento libertario americano. Por ello se podrá decir que entonces, el héroe resulta la mejor gestación del intelecto........

\section{LAS PROMESAS INCUMPLIDÁS. de Letras \\ "Jorge Puccinelli Converso"}

Muchas veces cabe lamentar que el Perú es un libro abierto de promesas incumplidas. Somos sin duda una de las más trágicas paradojas históricas de América.

Difícil resulta pensar que el Reglamento de Huaura, es la primera carta constitucional de América Hispana. A excepción de Colombia que clicta su primera constitución en 1821, ningún país se acerca tanto al Perú en esta primacía. Méxica no tendría Constitución hasta 1824 , Uruguay hasta 1829 y Chile hasta 1833.

Sin embargo nada más violentado y menos antiguo siempre que una constitución peruana (21).

La primera Universidad de América se establece en Lima aunque los mexicanos reclamen que la suya abre sus puertas primero. Sin embargo, el afecto a la antiguedad no ha sido gozado en esta tierra. La historia no recibe el aliento vital que se le dará en Chile, por ejemplo. El hombre que ahoga su vida en el pasado, aquel que sabe templar los párpados sobre arrugados pergaminos; en fin, quien busca la 
incógnita del ayer, es el menos favorecido por el estímulo y el fervor, y su nombre vése muchas veces adjetivado como símbolo de lo que no debe ser.

No bien hemos sido libres, se nos da una biblioteca. Se nos abren, como se ha dicho, las puertas a la cultura de todos los tiempos. Sin embargo, el don inestimable de la cultura resulta muy mencspreciado o a lo sumo esquematizado de modo enervante. País éste donde la ciencia se oficializa y se creen encontrar mirándolas capaces de condensar Pachakutecs con Echeniques en un solo y prodigioso saber individual.

Cuando alguna vez se escribe que el Perú es un mendigo sentado sobre un banco de oro, se yerra dos veces. Ni el Perú es un mendigo, ni el banco es de oro. Somos un hombre fatigado por la ociosidad secular que duerme sobre un banco de piedra. No se duda que hay orc en aquel banco. Sí lo hay, pero muy en la entraña. Sacarle es un esfuerzo titático. Y si lo hemos dejado ahí, no es por falta de intención sino porque aún no hemos aprendido a hacerlo.

No haya de confundirse pesar con pesimismo. Por lo transcurrido cabe sentir amargura. No obstante, ciertos hechos del pasado y algunos del presente reconfortan y tonifican el espíritu. Hay inmensas posibilidades materiales que surgen y algunas realizadas ya. La riqueza inexplorada de núestro sueloempieza á señalar cifras en el erario narcional. Y nadie sensatamente puede dudar del mágico poder que tiene la prosperidad.

La educación popular tiene $\mathrm{y} a$, muchas veces, el deseado recinto de ladrillo, aire y luz. Falta aún, el maestro. Sin embargo, un sentido movimiento se ha iniciado. He ahí una promesa que podrá cumplirse con ciento treinta años de atraso.

En cuanto a lo constitucional, el esfuerzo de 1823 ha resultado vano, muchas veces. ¿Podremos cumplir aquella promesa? He ahí una interragante imposibile de responder.

Y lo que es de mayor trascendencia aún, el respeto del hombre por el hombre ¿es algo qué conoceremos algún día? Para ello se requiere algo, acaso lo más bregoso de hallar en esta aventura de la vida, el soplo inestimable de una caridad cristiana que enseña más que tolerancia, amor humano sedimento esencial que alienta al hombre $\alpha$ ser verdaderamente hombre. 


\section{NOTAS}

(1) G. Je Bon : "Psicología de las Multitudes", Ed. Bs. As. 1942, pág. 48.

(2) Auguste Gomtc : "Discurso sobre el Espiritu Positivo", Edic. Madrid, 1934, pág. $1+\hat{3}$.

(3) Javier Prado Ugartcehe : Estado Social del Perú Durante la Denominación Española", Edic. Lima r941, pág. I85.

(4) 'Jorge Cornejo Bonroncle : "Túpac Amarı", Edic. Cuzco 1949, pígs, 13 : +4 .

'(5) J. C. Mariátegui : "El problema de la tierra", Edición de los sicte ensayos Lima, ada. edición, pág. +7.

(6) Jorge Basadre : "Perú, Problema y Posibilidad", Edic. Rosay, pág. 7 .

(7) Jose M. Valega : "La Gesta Emancipadern", Tomo I, pág. 52.

(8) "Memorias y Documentos para la Ilistoria de la Independencia del Peró", celic. París I 858 , pág. I 6 .

(9) Revue des Mondes, citado por Alcides Arguedas; Historia General de Bolivia, edic. La Paz rgaz, pág. IIL.

(ro) Sebastián Lorente : "Historia del/Períbajo los berbones". Valga advertir la relatividad de aquellas cifras. Distan de ser exactas pero of recen cuando menos, idea despejada de aproximación.

(ir) "Conflicto y armonía de las razas en América", tomo I, pág. 32x. Edlic. Buenos Aires, is83.

(12) "I.os Peruanos y su Independencia", Edic. Lima, I906.

(13) "Historia del Perú", Edic. r953, pág. 91.

(it) id. id. pig. 89iblioteca de Letras

(15) Edición de $18 z+$, pág. 2 .

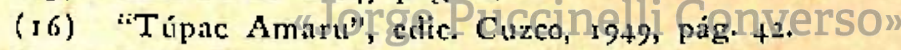

(17) Edlic. Lima, 1949, pág. I21.

(18) Edic. Buenos Aires, 1890 , pág. 62, II Tomo.

(19) "Simientes para un ensayo sobre la guerra de la independencia hispanoamericana". Edic. Lima, 1928.

(20) "La Tradición de Amériça", Buenos Aires, 3953, pág. 205.

(21) A excepción de La Carta de 1860 , todis tienen duración vacilante y cfimera. 